\title{
Dry Matter Production Response of Non-conventional Pineapple (Ananas comosus L.) Seedling to Nursery Media Preparation
}

\author{
Leta Ajema, Kidist Shewangizaw \\ Ethiopia Institute of Agricultural Research, Addis Ababa, Ethiopia
}

Email address:

letajema@gmail.com (L. Ajema),kidy8080@mail.com (K. Shewangizaw)

To cite this article:

Leta Ajema, Kidist Shewangizaw. Dry Matter Production Response of Non-conventional Pineapple (Ananas comosus L.) Seedling to Nursery Media Preparation. European Journal of Biophysics. Vol. 9, No. 1, 2021, pp. 9-12. doi: 10.11648/j.ejb.20210901.12

Received: January 3, 2021; Accepted: January 19, 2021; Published: March 12, 2021

\begin{abstract}
Establishment and management of pineapple production mainly lie on the production and supply of quality planting material with desirable root and shoot growth characteristics. Farmers in the South Ethiopia, uses different parts of pineapple like ground sucker, slips, and also crown sucker to transplant to the permanent fields. The fertilization practices were also not common, some farmers use to apply organic fertilizers like animal dung at the permanent field while there is no any media information generated to seedling production. Therefore, this study was conducted to examine the dry matter Production responses of non-conventional pineapple Seedling to organic based nursery media Preparation. The experiment was arranged in RCBD with three replication and six treatments. Six treatment combinations of compost to topsoil ratio in $(0: 1),(1: 1),(1: 2)$, (1:3) (1:4) and compost only (1:0). All the relevant parameters were collected and computed using SAS software. Treatment means were separated using LSD at $5 \%$ probability. The results revealed significant variation among the treatments that indicated, the soil based nursery media of compost (1:0) and (1:1) ratio of compost to topsoil responded the best dry matter production response of pineapple seedling in terms of, leaf fresh weight, leaf dry weight, root dry weight and total plant dry biomass. This result suggested that compost (1:0) and or compost to topsoil in (1:1) ratios was useful media to produce the best growth of pineapple seedling before transplanting to its production field.
\end{abstract}

Keywords: Biomass, Compost, Nursery Media, Pineapple Seedling

\section{Introduction}

Pineapple (Ananascomosus L. Merr.) belongs to Bromeliaceae family, which originated from South America, Southern Brazil, Northern Argentina and Praguay (Paull and Lobo, 2012) cited by Shamil et al., 2020 [1]. Pineapple (Ananas comosus L.) is the leading edible member of the Bromeliaceae family. In terms of its importance in global production, it ranks second among four major fresh tropical fruits, where it comes after mango and is followed by papaya and avocado [2]. Pineapple plants are usually propagated using vegetative planting material. There is a wide variety of types of vegetative planting material in which both cultivar and environment affect the availability and quality of material used to plant commercial fields [3]. The more common types of planting material produced naturally by the plants also referred to as conventional planting material, that include: a) Crowns from the top of the fruit; b) Slips from the peduncle; c) Suckers, which originate below the stem peduncle transition zone [4]. Non-conventional planting material could be obtained under field or nursery conditions by human interference applying specific techniques [3] like plantlets obtained by sectioning parts of the plant, which enables the development of lateral buds present along the stem of the mother plant or the small stem of the conventional types of planting material mentioned above [3].

Propagation by structures such as suckers, slips and crowns is very slow as a mother plant produces a limited number of suckers (three to five) and only one crown in a crop cycle of about 18 months. In view of the large quantity of planting material required for commercial plantings (approximately 44,000 up to 46,000 plants ha- 1 ), the producers are faced with the problem to get enough amount and uniform planting material that increasing the population of selected commercial 
variety in the shortest possible time. In order to produce the plantlets on a large scale, researchers have turned to utilizing tissue culture techniques to aid the cultivation of MD2 pineapple [5-7]. According to [7], an average of five plantlets per explant was produced in just one month of culture in the initiation media, which then further multiplied in the shootmultiplication media to produce three shoots per plantlet.

The lack of good quality planting material has limited the expansion and contributed to yield reduction of the pineapple culture in almost all pineapple producing areas of Ethiopia. Most pineapple producers in the Southern Ethiopia used to section the vegetative parts like (slip and ground sucker) to increase the planting material and to rapidly propagate the planting material for the selected variety (mostly smooth cayenne) and to raise the uniform and appropriate planting material within the nursery up to transplanting stage.

Some types of propagules are naturally produced by the plants and called conventional planting material. Its availability and quality depend on many factors, especially cultivar and environment [3]. They also indicated as Management techniques of this material have been continuously developed and will be addressed. However, even though there is a broad intention to solve the listed constraints, there is no nursery media information to get the appropriate seedling growing media. The maximum vegetative growths of those planting materials are determined by a function of genetic and environmental factors to produce shoot and root biomass. For a given genotype, maximum growth rate and yield can be obtained by environmental manipulation [8]. The crop environment (or microclimate) can be altered through management and soil fertility enhancement. Several studies have been done on the effect of soil fertility on pineapple growth and yield. But none of them examined the effect of nursery media preparation on dry matter production of pineapple seedling before transplanting. Understanding the factor determining the plant dry matter production and partitioning during the growth of pineapple and the relationship among plant growth parameters, environmental factors and cultural practices is necessary to produce a desired pineapple seedling before and after transplanting to the production field.

\section{Material and Methods}

\subsection{Experimental Materials}

Improved pineapple variety (smooth cayenne) ground slip was used as the seedling source as the mean yield for Smooth cayenne variety was more productive (70.4 tone ha-1) than other varieties [1]. The selected slips were sectioned into four uniform sizes. Top soil was collected from the surface of cultivable lands at $0-15 \mathrm{~cm}$ depth, dried crushed by pestle and mortar and sieved by $2 \mathrm{~mm}$ square mesh sieve. Compost was prepared from fresh coffee husk biomass with maize straw was added at the bottom of the prepared pit in about $5 \mathrm{~cm}$ thicknesses to keep a good ventilation; Immediately on the maize straws, fresh coffee husk residue was added to a thickness of about $20 \mathrm{~cm}$. Farm yard manure in $5 \mathrm{~cm}$ thickness to accelerate composting process and make the compost to have better nutritional composition and have abundant microorganism was added. Water was sprinkled after each layer as required to make the layers moist but not wet or soggy. The steps were repeated until the pit filled with the composting materials. Finally, the pit was covered with broad leaves banana and Enset leaves until every 21 days the materials was mixed and turned to next pit. After two times turning, i.e. after 63 days the compost was well decompose and ready as suggested by [9]. The prepared compost was air dried under shade, crushed, blended into powder and screened through $2 \mathrm{~mm}$ sieve and applied to the experiment. To determine its quality, initial chemical analysis for major plant nutrients and soil analysis was done.

\subsection{Experimental Design and Management Practices}

The experiment was arranged in a randomized complete block design (RCBD) with three replications to provide estimates of treatment effects or differences among treatment effects. Six treatment combinations of compost to topsoil ratio in $(0: 1),(1: 1),(1: 2),(1: 3),(1: 4)$ and Compost only (1:0) ratios by $(\mathrm{v} / \mathrm{v})$ were used as the experimental treatments. The top soil $(0: 1)$ and compost (1:0) were used as a control for the other treatments. All management practices like weeding, watering, were applied throughout the study period until the seedling attains its transplanting stage.

\subsection{Data Collection and Data Analysis}

The destructive data were recorded at the end of the experiment. Shoot and root parts of the seedlings were separated by cutting plant at the collar point using scissors and their fresh weights were measured by sensitive balance and expressed in gram per plant. The dry biomasses were recorded after the seedling air dried and attain the constant weight. Pineapple seedling dry parameters were recorded using a sensitive balance. Each plant parts were recorded separately. Finally, all the measured growth parameters were summarized and subjected to analysis of variance appropriate to RCBD were done using the General Linear Model (GLM). List Significant difference (LSD) at 5\% probability level was used to mean separation when analysis of variance indicated the presence of significant differences.

\section{Result and Discussion}

\subsection{Average Leaf Fresh and Dry Weight (g)}

The analysis of variance (ANOVA) of the mean result indicate that, both leaf fresh and dry weight $(\mathrm{g})$ of pineapple seedling were significantly $(\mathrm{P}<0.05)$ affected due to the applied compost to top soil treatments. Statically the highest mean leaf fresh weight were recorded from the plot treated by only compost $\left(128.62 \mathrm{~g} \mathrm{plant}^{-1}\right)$ as compared to the seedling mean leaf fresh weight raised on the mixture of one to one $\left(106.66 \mathrm{~g} \mathrm{plant}^{-1}\right)$, one to two $\left(93.23 \mathrm{~g} \mathrm{plant}^{-1}\right)$ one to three $\left(92.19 \mathrm{~g} \mathrm{plant}^{-1}\right)$, one to four $\left(91.06 \mathrm{~g} \mathrm{plant}^{-1}\right)$ and only 
topsoil (89.36 g plant $^{-1}$ ) ratio of medium (Figure 1). Similarly, there was a media effect observed on the recorded leaf dry weight among each treatment (Figure 1). The highest leaf dry weight were recorded from compost only (30.04g plant ${ }^{-1}$ ) followed by the plot treated by one to one $\left(21.66 \mathrm{~g} \mathrm{plant}^{-1}\right)$ ratio of compost to top soil application while the minimum leaf dry weight were recorded from the plot treated with topsoil only (9.94g plant ${ }^{-1}$ ) (Figure 1).

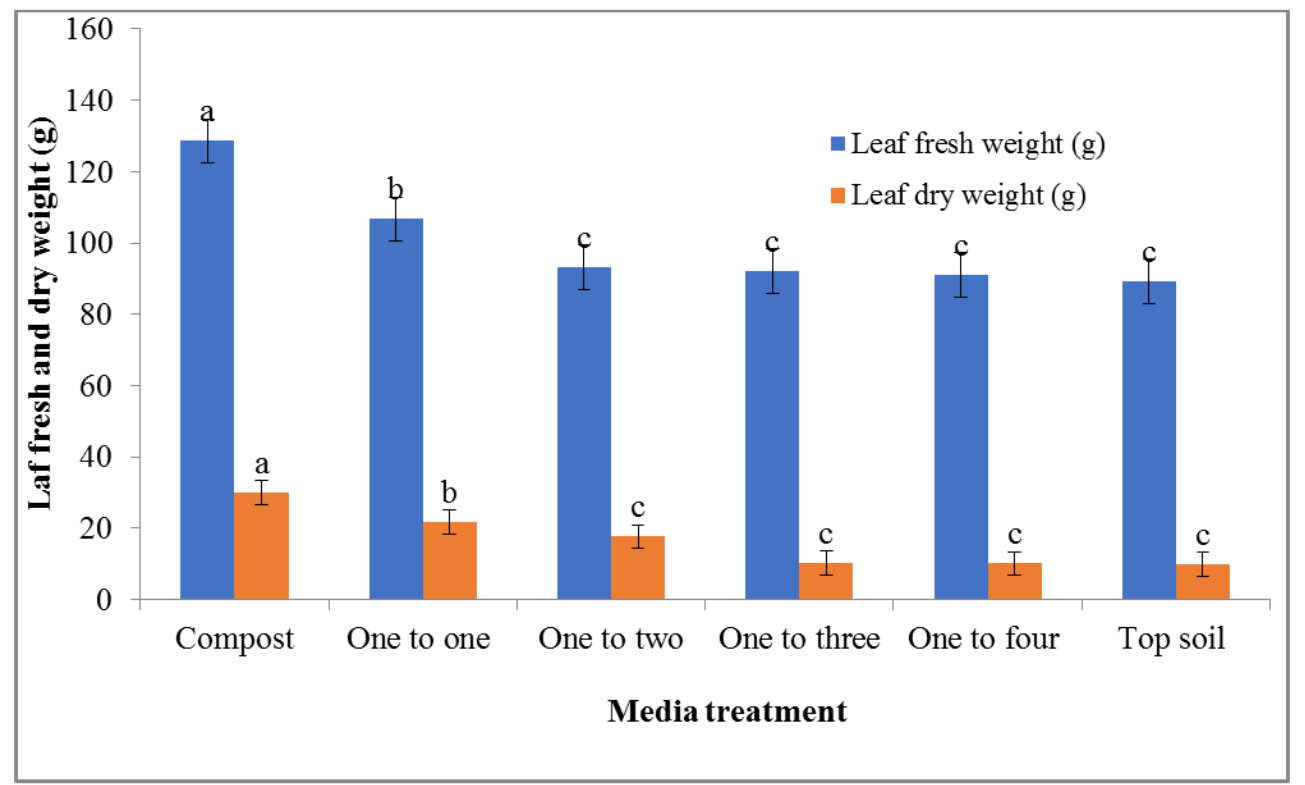

Figure 1. Mean Result of Leaf fresh and dry weight of pineapple seedling; Means with the same letter are not significantly different.

\subsection{Average Root Fresh and Dry Weight (g)}

Mean result of root fresh weight of pineapple seedling was significantly $(\mathrm{P}<0.05)$ affected by compost to top soil application ratio of soil media used to raise the pineapple seedling. The largest and significantly different root fresh weight was collected from the media prepared from only compost $\left(3.55 \mathrm{~g} \mathrm{plant}^{-1}\right)$ treatment followed by one to one $\left(2.72 \mathrm{~g} \mathrm{plant}^{-1}\right)$ ratio of compost to top soil media preparation. On the other hand, the media prepared without compost and or top soil $\left(1.95 \mathrm{~g}\right.$ plant $\left.^{-1}\right)$ respond the minimum result as compared to other treatment (Table 1). The root mean dry weight of pineapple seedling was also highly significantly $(\mathrm{P}<0.01)$ affected by compost to top soil application ratio of soil media used to raise the pineapple seedling (Table 1). The largest root dry weight was collected from the medium prepared from only compost $\left(0.79\right.$ gplant $\left.^{-1}\right)$ treatment followed by one to one $\left(0.60 \mathrm{~g} \mathrm{plant}^{-1}\right)$ and one to two $(0.60 \mathrm{~g}$ plant $\left.^{-1}\right)$ ratio of compost to top soil prepared media. On the other hand, the media prepared from top soil only $(0.39 \mathrm{~g}$ plant $\left.^{-1}\right)$ was able to respond the minimum root dry weight (Table 1). The result in line with [10] indicated the result on the effect of planting media on the growth of pineapple seedling. Mean result of total plant dry biomass of pineapple seedling were also significantly $(\mathrm{P}<0.01)$ affected by compost to top soil application ratio of soil medium used to raise the pineapple seedling. Similar to the other growth indicating parameters, the largest (30.85) total dry biomass was record from the plot treated with the soil medium prepared from compost only followed by one to one (22.26) ratio of compost to top soil medium while the minimum was recorded from the only topsoil (10.34) medium used to raise the seedling. The result is in line with the findings of [11] careful soil preparation is important to enable adequate growth and a deep pineapple root system, with which poor tilth is rather limited and superficial. According to [12] reported that sectioning and planting the sectioned plant let within the compost and or organic riches soil growth media system enabled the production of about thirty plantlets 25 to $30 \mathrm{~cm}$ long, from each stem within six to ten months after planting the sections; however, they emphasized that this yield was variable depending on the cultivar used, the storage reserves of the stem, the environmental conditions and the cultural practices applied. A good supply of organic matter in the soil and its protection with a biomass cover is also highly beneficial for pineapple crop development [13]. Therefore, multiplication and dissemination of this variety may enhance the production and productivity of pineapple in the area recommended by [1] could be propagated at a nursery with a compost nursery media to produce a large number of seedlings with a uniform growth stage [14-16].

Table 1. Mean result of root fresh and dry weight and Total dry weight of pineapple seedling.

\begin{tabular}{llll}
\hline Treatments & $\begin{array}{l}\text { Root fresh } \\
\text { weight }(\mathbf{g})\end{array}$ & $\begin{array}{l}\text { Root dry weight } \\
(\mathbf{g})\end{array}$ & $\begin{array}{l}\text { Total dry weight } \\
(\mathbf{g})\end{array}$ \\
\hline Compost & $3.55^{\mathrm{a}}$ & $0.79^{\mathrm{a}}$ & $30.85^{\mathrm{a}}$ \\
One to one & $2.72^{\mathrm{b}}$ & $0.60^{\mathrm{b}}$ & $22.26^{\mathrm{b}}$ \\
One to two & $1.99^{\mathrm{c}}$ & $0.60^{\mathrm{b}}$ & $18.26^{\mathrm{c}}$ \\
One to three & $1.95^{\mathrm{c}}$ & $0.43^{\mathrm{c}}$ & $10.65^{\mathrm{d}}$ \\
One to four & $1.91^{\mathrm{c}}$ & $0.40^{\mathrm{c}}$ & $10.52^{\mathrm{d}}$ \\
Top soil & $1.87^{\mathrm{c}}$ & $0.39^{\mathrm{c}}$ & $10.34^{\mathrm{d}}$ \\
CV $(\%)$ & 12.55 & 4.52 & 10.62 \\
LSD $(0.05)$ & 0.53 & 0.044 & 3.31 \\
\hline
\end{tabular}

Means with the same letter are not significantly different. 


\section{Conclusion and Recommendation}

Stem sectioning has been especially interesting, as it is mostly done using propagules part like ground sucker, slip and or crown sucker available at low cost, and is a rather simple method suited for multiplication and production of disease-free and uniform planting material in nurseries. Media composition used as treatment was influenced the general dry matter accumulation of pineapple seeding at nursery stage before transplanting to the permanent field. The current trail indicates that, it is very important to raise the best seedling growth or planting material of pineapple with organic compost used as nursery media. Pineapple seedlings performed better in soil growth media containing compost in all parameters observed in this research work. The result generated from this work, indicate that, there is a significant differences among the treatments used (compost, a ratio of compost to top soil and topsoil only) growth media used to raise the pineapple seedling at the nursery stage before transplanting to the permanent field in leaf fresh and dry weight, root fresh and dry weight and total plant dry biomass. Therefore, it is recommendable that compost or organic manure media should be used to grow pineapple seedlings at the nursery stage to raise well performing seedlings before transplanting to the permanent field. In addition, it needs to be further studied in order to reduce costs of production and to improve the agronomic performance of the plantlets for establishing commercial pineapple fields in the future.

\section{References}

[1] Shamil A; Abebe G; Dereje G; Wakjira G 2019. Evaluation of Pineapple (Ananas comosus L.) Varieties at Teppi, South Western Ethiopia. Greener Journal of Agricultural Sciences 9 (4): 357-360, https://doi.org/10.15580/ GJAS.4.032619053.

[2] FAO. Food Outlook: Biannual Report on Global Food Markets; Food and Agriculture Organization of the United Nations: Rome, Italy, 2017; pp. 69-81.

[3] Domingo Haroldo R. C. Reinhardt, Duane P. Bartholomew, Fernanda Vidigal Duarte Souza, 2018. Advances in pineapple plant propagation. Rev. Bras. Frutic., Jaboticabal, v. 40, n. 6: (e-302).

[4] Reinhardt D. H., Souza A. P. M., Caldas (2004a). Management of slips and its effect on growth and production of Pérola pineapple plants. Rev. Bras. Frutic. 25, 248-252.
[5] Halim, N. A. A.; Ramasamy, S.; Tan, B. C.; Khalid, N.; Yaacob, J. S. 2018. In vitro shoot regeneration and analysis of biochemical, antioxidant and anticancer properties of Ananas comosus var. Md2. Malays. J. Fundam. Appl. Sci., 14: 263268.

[6] Nelson, B. J.; Asare, P. A.; Junior, R. A. 2015. In vitro growth and multiplication of pineapple under different duration of sterilization and different concentrations of benzylaminopurine and sucrose. Biotechnology. 14: 35-40.

[7] Hamid, N. S.; Bukhori, M. F. M.; M. 2013. Direct and indirect plant regenerations of pineapple var. $\mathrm{Md} 2$ (Ananas comosus L.). Malays. Appl. Biol. 42, 61-66.

[8] Dveas, J. C (2012). Pineapple development and growth media. Plant physiology, 201, 34-38.

[9] Solomon Endris. 2006. Accelerated composting of coffee processing by products: an organic option for soil fertility management in the coffee based cropping system of south western Ethiopia. Proceeding of $21^{\text {st }}$ International scientific conference on coffee science Montpelier, France, pp 10841089.

[10] Indriyani, N. L. P., Hadiati, S. and Soemargono, A., 2011. The effect of planting medium on the growth of pineapple seedling. Journal of Agricultural and Biological Science. 6 (2), pp. 4348.

[11] Rev. Bras. Frutic., Jaboticabal, 2018, v. 40, n. 6: (e-302).

[12] JUNGHANS, T. G.; JUNGHANS, D. T.; MATOS, E. M.; BATISTA, E. A.; MIELKE, M. S.; LEDO, C. A. S. 2015. Seed germination of three pineapple progenies in different temperature regimes. Perspectiva, Erechim, v. 39, n. 147, p. 61-67.

[13] Mahmud, M.; Abdullah, R.; Yaacob, J. S. 2018. Effect of Vermicompost Amendment on Nutritional Status of Sandy Loam Soil, Growth Performance, and Yield of Pineapple (Ananas comosus var. MD2) under Field Conditions. Agronomy. 3 (8): 183.

[14] Akanbi, J (2012). Soil organic matter and its role in crop development. Science 253, 3114-3118.

[15] CUNHA, G. A. P. da; MATOS, A. P. de; SANCHES,. Cruz das Almas, BA: EMBRAPA-CNPMF, 2004a. 30p. (Circular Técnica, 01).

[16] Leta A, Negesse T, 2020. Growth and Biomass production Response of Pineapple (Ananas Comosus L.) Seedling to Compost with Top Soil Ratio Nursery Media Preparation. International Journal of Research in Agriculture and Forestry, 7 (11): 06-12 